\title{
Research on volume determination of mass standards with two acoustic measuring chambers
}

\author{
Man Hong Hu, Jian Wang, Yue Zhang, Chang Qing Cai, Rui Lin Zhong, Jing An Ding, and Xiao Ping Ren \\ Division of Mechanics and Acoustic, National Institute of Metrology, No.18, Bei San Huan Dong Lu, Chaoyang Dist, Beijing, P.R.China
}

ABSTRACT

The acoustic volume measuring method is a promising non-contact method for volume determination of mass weights. To improve the measuring accuracy of volume determination with the non-contact acoustic method, an acoustic measuring system with two measuring chambers is newly designed to compensate for the non-linearity measuring errors. When reducing the remaining air in the measuring chamber, the measuring accuracy can be greatly reduced. The volumes of mass standards ranging from $100 \mathrm{~g}$ to $5 \mathrm{~kg}$ are tested to evaluate the non-linearity errors of the volume measurement. The relative uncertainties of the acoustic volume determination are below $7.0 \times 10^{-4}(k=2)$.

\section{Section: RESEARCH PAPER}

Keywords: mass standard; volume measurement; acoustic method

Citation: Man Hong Hu, Jian Wang, Yue Zhang, Chang Qing Cai, Rui Lin Zhong, Jing An Ding, and Xiao Ping Ren, Research on volume determination of mass standards with two acoustic measuring chambers, Acta IMEKO, vol. 6, no. 2, article 3, July 2017, identifier: IMEKO-ACTA-06 (2017)-02-03

Section Editor: Min-Seok Kim, Research Institute of Standards and Science, Korea

Received March 19, 2016; In final form October 22, 2016; Published July 2017

Copyright: @ 2017 IMEKO. This is an open-access article distributed under the terms of the Creative Commons Attribution 3.0 License, which permits unrestricted use, distribution, and reproduction in any medium, provided the original author and source are credited

Funding: This work was supported by natural science foundation of china (NSFC) (Grant No. 51205379), P.R. China

Corresponding author: Hu Manhong, e-mail: hmh@nim.ac.cn

\section{INTRODUCTION}

For the mass measurement of a weight, the ABBA cycle on a mass comparator is used, in which $A$ is the reference (standard) mass weight and B is the test mass weight. The mass comparison is usually carried out in air, based on the difference of the gravitational force caused by the standard or test weight on the mass comparator. The air bouncy can contribute a big uncertainty especially in the high accuracy mass measurement such as the prototype level or $E_{1}$ class level. Thus the mass standard's volume needs to be precisely determined for the air buoyancy correction [1].

There are many measurement technologies such as the hydrostatic method, the dimension measuring method and the acoustic method. Although the measuring accuracy cannot be on the same level as the hydrostatic method (usually with relative combined uncertainty as low as $\left.1 \times 10^{-6}(k=1)\right)$, the acoustic method is a promising volume measuring method because there is no contact with mass standards during the whole volume measuring procedure, especially for the weights with non-regular shape and 3D curved surfaces. Both the standard weights and test weights don't need to be immersed in any liquid.

M. Ueki et al. firstly developed an acoustic measuring system to determine the volume of mass weights ranging from $1 \mathrm{~g}$ to $10 \mathrm{~kg}$ at the National Metrology Institute of Japan (NMIJ) [2][6]. For the weights with nominal value ranging from $100 \mathrm{~g}$ to $10 \mathrm{~kg}$, a relative uncertainty of $1 \times 10^{-3}(k=2)$ is achieved. For weights ranging from $1 \mathrm{~g}$ to $100 \mathrm{~g}$, the measuring combined standard uncertainty is below $0.0021 \mathrm{~cm}^{3}$ [2]-[5]. An acoustic volume measuring system has also been designed at the National Institute of Metrology China (NIM) to extend the measurement range of the nominal value of mass weights up to $20 \mathrm{~kg}$ [7]. However, since the air inside the chamber does not change perfectly adiabatically (necessary to get a high measuring accuracy), the ratio of shape and volume of the reference weight needs to be similar to that of the test weight. Otherwise a large non-linearity measurement error will be introduced to the measuring process.

To investigate the non-linearity contribution in the acoustic measuring method, an acoustic measuring system with two measuring chambers is designed by the National Institute of Metrology China. The volumes of mass standards ranging from 
$200 \mathrm{~g}$ to $5 \mathrm{~kg}$ are tested to evaluate the non-linearity errors of the acoustic measuring process.

\section{EXPERIMENTAL APPARATUS AND MEASURING PROCEDURE}

\subsection{Experimental apparatus}

The acoustic method is based on gas compressibility laws. Assuming the gas changes adiabatically, the air pressure, $P$, has a constant relation with the volume of air, $V$, as expressed in (1):

$$
P \times V^{\gamma}=\text { cons }
$$

Here, $\gamma$ is the ratio of the specific heats, which is 1.40 at atmospheric pressure and room temperature. The newly designed measuring apparatus made of aluminum alloy with two measuring chambers is shown in Figure 1.

A sinusoidal drive signal from a signal generator is applied to a loudspeaker between the two measuring chambers. This will alternately generate a compression wave with inverse phase in the left chamber and the right chamber.

Two sound pressure sensors (also called microphones) are used to separately measure the pressure changes, that is, $\Delta P_{1}$ in the left chamber and $\Delta P_{2}$ in the right chamber, respectively, as shown in (2) and (3), where $P_{0}$ is the air pressure in the chamber. The output signals from two microphones, $e_{1}$ and $e_{2}$, are converted into digital signals and sent to a computer for sound pressure calculation. The resulting sound pressure $\Delta P_{x}$ is measured. The ratio of the pressures $R_{n}$ can be calculated as $\Delta P_{1} / \Delta P_{2}[3]$.

$$
\begin{aligned}
& \frac{\Delta P_{1}}{P_{0}}=\gamma \frac{\Delta V}{V_{01}} \\
& \frac{\Delta P_{2}}{P_{0}}=\gamma \frac{\Delta V}{V_{02}}
\end{aligned}
$$

\subsection{Measurement Results}

When measuring the volume with the acoustic method, it is assumed that air changes adiabatically in the two measurement chambers [2]-[7]. However, air near the surface of the test weight or reference weight and the wall of the containers changes isothermally [3]. Thus, during the measurement, the actual displaced volume in the chamber by the test weight, $V_{\mathrm{t} 0}$ and the reference weight, $V_{\mathrm{r} 0}$ can be expressed with (4) and (5).

$V_{t 0}=V_{t}-d S_{t}$

$V_{r 0}=V_{r}-d S_{r}$

where $S_{t}$ and $S_{\mathrm{r}}$ are the surface area of the test weight and reference weight, and $d$ is the thickness of the air isothermal

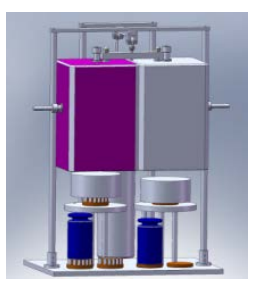

a)

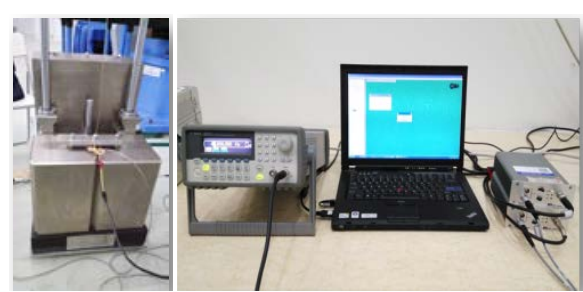

b)
Figure 1. Schematic and pictures of the new measuring apparatus with two measuring chambers. layer [5].

The effect of surface area to the volume measurement is not considered firstly, and it means that $V_{\mathrm{t} 0} \approx V_{\mathrm{t}}$, and $V_{\mathrm{r} 0} \approx V_{\mathrm{r}}$. Based on the measuring sequence in Figure 2, (6)-(8) can be derived. Thus, the volume of the test weight, $V_{\mathrm{t}}$, can be calculated with (9). This equation is used to evaluate the nonlinearity error caused by the effect of the weight's surface [3].

$R_{1}=\frac{\Delta P_{1}}{\Delta P_{2}}=\frac{V_{02}-V_{t}}{V_{01}-V_{r}}$

$R_{2}=\frac{\Delta P_{1}}{\Delta P_{2}}=\frac{V_{02}-V_{r}}{V_{01}-V_{t}}$

$R_{3}=\frac{\Delta P_{1}}{\Delta P_{2}}=\frac{V_{02}-V_{t}-V_{r}}{V_{01}}$

$V_{t}=V_{r} \times \frac{\left(R_{2}-R_{3}\right)\left(1+R_{1}\right)}{\left(R_{1}-R_{3}\right)\left(1+R_{2}\right)}$

\section{MEASUREMENT RESULTS AND UNCERTAINTY ANALYSIS}

\subsection{Measuring Results}

According to (9), the amplitude ratio $R$ is the key parameter for the acoustic volume measurement. As the driving signal to the loudspeaker showed in Figure 3, the amplitude and frequency of the sinusoidal signal should be carefully chosen to achieve the best measurement of sound pressure and the amplitude ratio $R$.

Figure 4 shows the relationship between $R$ and the amplitude and frequency of the sinusoidal signal using two measuring chambers. For each amplitude and frequency, 100 samples of sound pressure are acquired. It can be seen that to obtain a repeatability of $R$ better than $1 \times 10^{-4}$, the amplitude of the sinusoidal drive signal should be between $1.6 \mathrm{~V}$ and $1.9 \mathrm{~V}$,

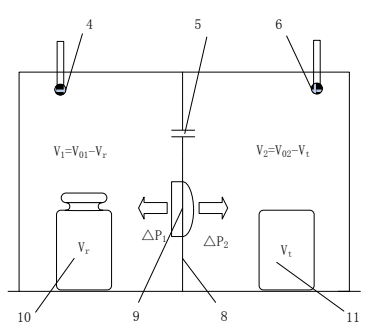

a)

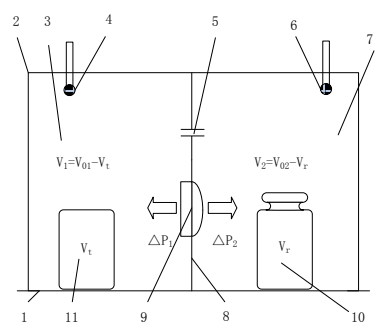

b)

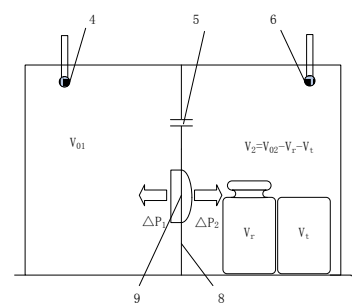

c)

Figure 2. The schematic of procedures $(a, b, c)$ of the measuring process, in which 1: Bottom of measuring chamber; 2: Side walls of measuring chamber; 3: Left measuring chamber; 4: Sound pressure sensor 1; 5: Connecting tube; 6: Sound pressure sensor 2; 7: Right measuring chamber; 8: Separating wall; 9: Loudspeaker; 10: Reference weight; 11:Test weight. 


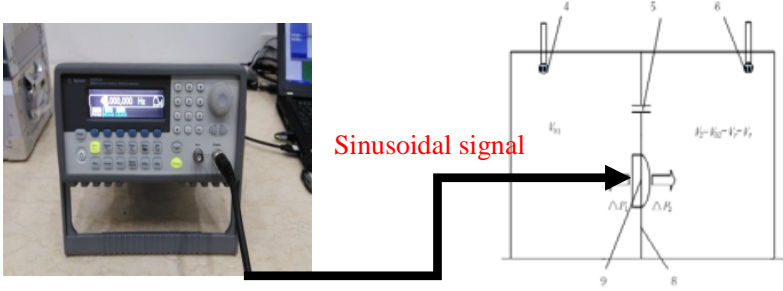

Figure 3. Schematic of the connection of the signal generator to the loudspeaker.

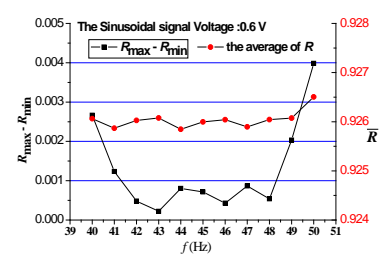

a)

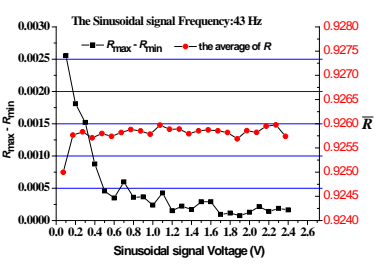

b)
Figure 4. Relationship between $R$ and the amplifier or frequency of the sinusoidal signal.

and the frequency should be $43 \mathrm{~Hz}$. The parameters used for the mass volume measurement are shown in Table 1.

According to (9), as shown in Figure 5 to evaluate the nonlinearity errors, a nominal mass weight of $100 \mathrm{~g}$ is used as the reference weight, and nominal mass weights ranging from $200 \mathrm{~g}$ to $5 \mathrm{~kg}$ are measured with the 3-step method showed in Figure 2. The non-linearity error is expressed as the deviation of the measurement value from the acoustic method to the volume measuring value from the hydrostatic method. With the same reference weight, the non-linearity error of the measured volume of the test weight increases with its nominal value.

As also shown in Figure 6, a test weight with a nominal value of $2 \mathrm{~kg}$ is used as the test weight, and weights ranging from $100 \mathrm{~g}$ to $1 \mathrm{~kg}$ are used as the reference weight. The nonlinearity error of the measured volume of $2 \mathrm{~kg}$ weight decreases when the nominal value of the reference weight increases.

Based on the analysis in Figure 5 and Figure 6 , it can be

Table 1. Parameters used for the volume measurement

\begin{tabular}{lc}
\hline \multicolumn{1}{c}{ Parameters } & $\begin{array}{c}\text { Configuration of the sinusoidal } \\
\text { signal }\end{array}$ \\
\hline Gain of left chamber $(\mathrm{dB})$ & 20 \\
Gain of right chamber $(\mathrm{dB})$ & 20 \\
Sinusoidal signal frequency $(\mathrm{Hz})$ & 43 \\
Sinusoidal signal voltage $(\mathrm{V})$ & $1.6 \sim 1.9$ \\
\hline
\end{tabular}

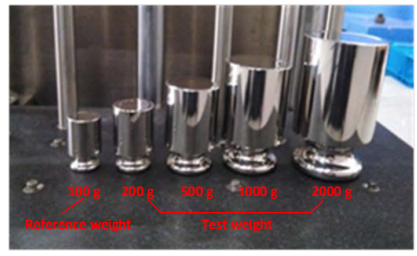

a)

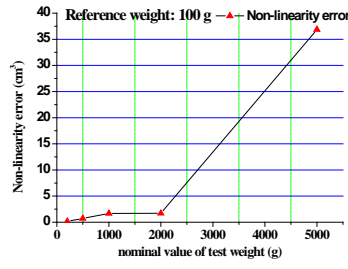

b)
Figure 5. The reference weight of $100 \mathrm{~g}$ and test weights ranging from 200 $\mathrm{g}$ to $5 \mathrm{~kg} \mathrm{(a)}$ and the measuring results (b).

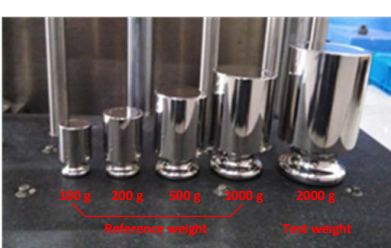

a)

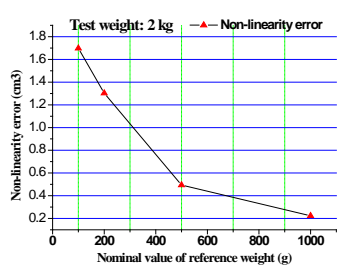

b)
Figure 6 . The reference weights ranging from $100 \mathrm{~g}$ to $1 \mathrm{~kg}$ and test weight of $2 \mathrm{~kg} \mathrm{(a)} \mathrm{and} \mathrm{the} \mathrm{measurement} \mathrm{results} \mathrm{(b).}$

concluded that the larger the difference between the volume, surface or the ratio of volume and surface of the reference weight and the test weight, the higher the non-linearity of the acoustic measuring method can be introduced. If the effect of the weight surface can be compensated, the accuracy of the acoustic volume method can be improved significantly.

To evaluate the effect of the weight surface and to improve the volume measuring accuracy, certain artefacts were put into both measuring containers separately as shown in Figure 7(a) to reduce the volume of air remained in the two containers. The tests weights ranging from $100 \mathrm{~g}$ to $5 \mathrm{~kg}$ are measured with a 1 $\mathrm{kg}$ reference weight. The non-linearity errors were evaluated to investigate the effects of weights' surface. The non-linearity error was defined as the deviation between the volume measured by the acoustic method and the volume measured by the hydrostatic method. The results are shown in Figure 7(c). From $100 \mathrm{~g}$ to $5 \mathrm{~kg}$, the non-linearity error shows no significant difference when the surface ratio between the test weight and reference weight changes.

\subsection{Uncertainty Analysis}

According to (9), describing the calculation of the volume, there are four main uncertainty contribution factors which are the reference weight's volume, $R_{1}, R_{2}$ and $R_{3}$. The uncertainty budget of the volume of the $200 \mathrm{~g}$ weight using the $100 \mathrm{~g}$ weight as reference weight is shown in Table 2.

With the same uncertainty evaluation method, the volume uncertainty evaluation results of weights ranging from $200 \mathrm{~g}$ to $5 \mathrm{~kg}$ are shown in Table 3, and the relative extended uncertainties show no significant differences for the big contribution of the non-linearity error during the volume measuring process. The volume uncertainties of the $2 \mathrm{~kg}$ weight using different reference weights are shown in Table 4. The

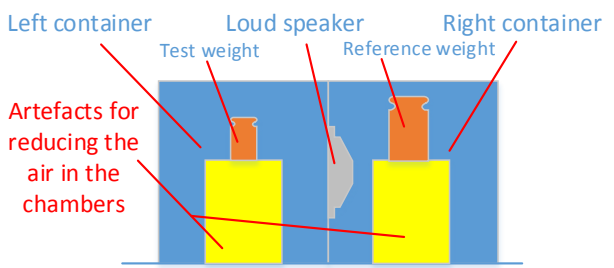

a)

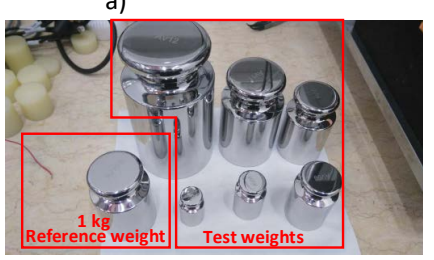

b)

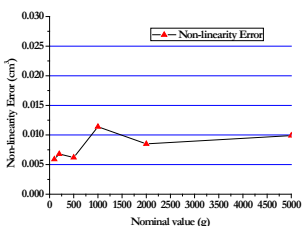

c)
Figure 7. Artefacts in the chamber (a) to reduce the remaining air in the chambers, the picture of $1 \mathrm{~kg}$ reference weight and test weights ranging from $100 \mathrm{~g}$ to $5 \mathrm{~kg}(\mathrm{~b})$ and the measuring results (c). 
Table 2. Uncertainty budget of the volume of $200 \mathrm{~g}$ weight using the $100 \mathrm{~g}$ weight as reference weight.

\begin{tabular}{lccc}
\hline \multicolumn{1}{c}{ Sources } & Uncertainty & $\begin{array}{c}\text { Sensitivity } \\
\text { coefficient }\end{array}$ & $\begin{array}{c}\text { Uncertainty } \\
\text { contribution }\end{array}$ \\
\hline Volume of reference weight & $0.0005 \mathrm{~cm}^{3}$ & 2 & $0.0010 \mathrm{~cm}^{3}$ \\
$R_{1}$ & 0.00001 & $11152 \mathrm{~cm}^{3}$ & $0.11 \mathrm{~cm}^{3}$ \\
$R_{2}$ & 0.00001 & $5545 \mathrm{~cm}^{3}$ & $0.06 \mathrm{~cm}^{3}$ \\
$R_{3}$ & 0.00001 & $16672 \mathrm{~cm}^{3}$ & $0.17 \mathrm{~cm}^{3}$ \\
Combined uncertainty & & & $0.21 \mathrm{~cm}^{3}$ \\
Expanded uncertainty $(k=2)$ & & & $0.42 \mathrm{~cm}^{3}$ \\
Relative expanded & & & 1.7 \\
uncertainty $\left(\times 10^{-2}, k=2\right)$ & & & \\
\hline
\end{tabular}

Table 3. Uncertainty budget of test weights using the $100 \mathrm{~g}$ weight as reference weight.

\begin{tabular}{|c|c|c|c|c|c|}
\hline \multirow{2}{*}{ Sources } & \multicolumn{5}{|c|}{ Test weights } \\
\hline & $5 \mathrm{~kg}$ & $2 \mathrm{~kg}$ & $1 \mathrm{~kg}$ & $500 \mathrm{~g}$ & $200 \mathrm{~g}$ \\
\hline $\begin{array}{l}\text { Volume of reference } \\
\text { weight }\left(\mathrm{cm}^{3}\right)\end{array}$ & 0.025 & 0.010 & 0.0050 & 0.0025 & 0.0010 \\
\hline$R_{1}\left(\mathrm{~cm}^{3}\right)$ & 3.14 & 1.2 & 0.53 & 0.27 & 0.11 \\
\hline$R_{2}\left(\mathrm{~cm}^{3}\right)$ & 0.06 & 0.06 & 0.05 & 0.05 & 0.06 \\
\hline$R_{3}\left(\mathrm{~cm}^{3}\right)$ & 3.20 & 1.17 & 0.59 & 0.32 & 0.17 \\
\hline $\begin{array}{c}\text { Combined } \\
\text { uncertainty }\left(\mathrm{cm}^{3}\right)\end{array}$ & 4.49 & 1.68 & 0.80 & 0.42 & 0.21 \\
\hline $\begin{array}{c}\text { Expanded } \\
\text { uncertainty }\left(\mathrm{cm}^{3}\right)\end{array}$ & 8.97 & 3.36 & 1.60 & 0.84 & 0.42 \\
\hline $\begin{array}{l}\text { Relative expanded } \\
\text { uncertainty }(k=2, \\
\left.\times 10^{-2}\right)\end{array}$ & 1.4 & 1.4 & 1.3 & 1.3 & 1.7 \\
\hline
\end{tabular}

relative expanded uncertainty decreases with the reference weight's nominal value, and this indicates that the non-linearity errors decrease in the same trend.

However, when the volume of air in both measuring chambers is reduced as shown in Figure 7(a), the measuring accuracy improved immediately, as shown in Table 5. All the relative expanded uncertainties are below $7.8 \times 10^{-4}(k=2)$. The volume of $5 \mathrm{~kg}$ weight is 500 times that of the $100 \mathrm{~g}$ weight. However there is no big difference between the volume measuring accuracy of the test weights with different nominal values ranging from $100 \mathrm{~g}$ to $5 \mathrm{~kg}$ using the same $2 \mathrm{~kg}$ weight as the reference weight.

Table 4. Uncertainty budget of the volume $2 \mathrm{~kg}$ weight using different reference weights.

\begin{tabular}{ccccc}
\hline Sources & \multicolumn{4}{c}{ Reference weights } \\
\cline { 2 - 5 } & $1 \mathrm{~kg}$ & $500 \mathrm{~g}$ & $200 \mathrm{~g}$ & $100 \mathrm{~g}$ \\
\hline $\begin{array}{c}\text { Volume of reference } \\
\text { weight }\left(\mathrm{cm}^{3}\right)\end{array}$ & 0.006 & 0.008 & 0.010 & 0.010 \\
$R_{1}\left(\mathrm{~cm}^{3}\right)$ & 0.11 & 0.22 & 0.55 & 1.18 \\
$R_{2}\left(\mathrm{~cm}^{3}\right)$ & 0.06 & 0.06 & 0.06 & 0.06 \\
$R_{3}\left(\mathrm{~cm}^{3}\right)$ & 0.16 & 0.27 & 0.60 & 1.17 \\
$\begin{array}{c}\text { Combined } \\
\text { uncertainty }\left(\mathrm{cm}^{3}\right)\end{array}$ & 0.21 & 0.36 & 0.9 & 1.7 \\
$\begin{array}{c}\text { Expanded } \\
\text { uncertainty }\left(\mathrm{cm}^{3}\right)\end{array}$ & 0.41 & 0.71 & 1.8 & 3.4 \\
$\begin{array}{c}\text { Relative expanded } \\
\text { uncertainty }\left(k=2, \times 10^{-2}\right)\end{array}$ & 0.4 & 1.2 & 7.2 & 27 \\
\hline
\end{tabular}

Table 5. Uncertainty budget of test weights using $1 \mathrm{~kg}$ weight as reference weight after reducing the air in the acoustic chambers.

\begin{tabular}{ccccccc}
\hline & \multicolumn{7}{c}{ Test weights } \\
\cline { 2 - 7 } Sources & $5 \mathrm{~kg}$ & $2 \mathrm{~kg}$ & $1 \mathrm{~kg}$ & $500 \mathrm{~g}$ & $200 \mathrm{~g}$ & $100 \mathrm{~g}$ \\
\hline $\begin{array}{c}\text { Volume of } \\
\text { reference } \\
\text { weight }\left(\mathrm{cm}^{3}\right)\end{array}$ & 0.015 & 0.006 & 0.003 & 0.002 & 0.001 & 0.0003 \\
$R_{1}\left(\mathrm{~cm}^{3}\right)$ & 0.068 & 0.028 & 0.017 & 0.009 & 0.005 & 0.002 \\
$R_{2}\left(\mathrm{~cm}^{3}\right)$ & 0.014 & 0.008 & 0.005 & 0.004 & 0.002 & 0.001 \\
$R_{3}\left(\mathrm{~cm}^{3}\right)$ & 0.084 & 0.041 & 0.026 & 0.012 & 0.006 & 0.003 \\
$\begin{array}{c}\text { Combined } \\
\text { uncertainty }\left(\mathrm{cm}^{3}\right)\end{array}$ & 0.110 & 0.051 & 0.032 & 0.016 & 0.008 & 0.004 \\
$\begin{array}{c}\text { Expanded } \\
\text { uncertainty }\left(\mathrm{cm}^{3}\right)\end{array}$ & 0.220 & 0.102 & 0.063 & 0.032 & 0.017 & 0.008 \\
$\begin{array}{c}\text { Relative expanded } \\
\text { uncertainty }(k=2, \\
\left.\times 10^{-2}\right)\end{array}$ & 0.036 & 0.041 & 0.050 & 0.052 & 0.068 & 0.064 \\
\hline
\end{tabular}

\section{CONCLUSIONS}

To investigate the non-linearity contribution in the acoustic measuring method, an acoustic measuring system with two measuring chambers is newly designed. The optimization of measurement parameters was investigated by analyzing the relationship between $R$ and the amplitude or frequency of sinusoidal signal. The volumes of mass standards ranging from $100 \mathrm{~g}$ to $5 \mathrm{~kg}$ are tested to evaluate the non-linearity errors of the acoustic measuring method.

When the air in the container is not adjusted, a poor volume measuring accuracy is achieved, the shape or surface/volume ratio will greatly influence the acoustic volume measuring accuracy.

The residual air in the measuring chambers has a big influence on the acoustic measuring accuracy. When the volume of air in the measuring chamber is reduced to a proper volume by using the new designed experimental setup, the measuring accuracy improved immediately, and the shape or surface/volume ratio is no longer the main uncertainty contribution during the volume determination using the acoustic method.

\section{ACKNOWLEDGEMENT}

This research is supported in part by natural science foundation of china (NSFC) (Grant No. 51205379), in part by the National Science and Technology Support Program under Grant 2011BAK15B06, in part by the NIM JBS scientific project 2015 and in part by National Key Research and Development Program for National Quality Infrastructure under Grant 2016YFF0200103.

\section{REFERENCES}

[1] Weights of classes E1, E2, F1, F2, M1, M1-2, M2, M2-3, and M3, OIML regulation R111, edition 2004 (E)

[2] M. Ueki, T. Kobata, S. Mizushima, Y. Nezu, A. Ooiwa and Y. Ishii, "Application of an acoustic volumeter to standard weights", 15th IMEKO World Congress, Osaka, 1999, pp. 213220.

[3] T. Kobata, M. Ueki, A. Ooiwa and Y. Ishii, "Mesurement of the volume of weights using an acoustic volumeter and the reliability of such measurement", Metrologia, 41(2004) pp. S75-S83.

[4] M. Ueki, T. Kobata, K. Ueda and A. Ooiwa, "Automated Volume Measurement for Weights using Acoustic Volumeter", 
20th Conference on Measurement of Force, Mass and Torque, Mexico, 2007.

[5] M. Ueki, T. Kobata, K. Ueda and A. Ooiwa, "Measurements of the volume of weights from $1 \mathrm{~g}$ to $50 \mathrm{~g}$ using an acoustic volumeter", SICE Annual Conference, Okayama, Japan, 2005, pp. 1742-1747.
[6] I. Torigoc and Y. Ishii, "Acoustic bridge volumeter", Trans.Soc.Instrum.ControlEng, E-1(2001) pp. 164-170.

[7] M.H. Hu, J. Wang, Y. Zhang, C.Q. Cai and X. L. Wang, "Experimental research on volume measurement method of weights based on acoustic principle", Chinese Journal of Scientific Instrument, 33(2012) pp. 2337-2342. 